\section{Pedro Bosch Gimpera}

\author{
Pedro Bosch Gimpera
}

M. ${ }^{a}$ Dolores Fernández-Posse de Arnaiz (*)

\section{RESUMEN}

Este artículo presenta un perfil intelectual de Pedro Bosch Gimpera. Revisa su formación académica, el ambiente social e intelectual en el que se desarrolló, su papel en la institucionalización de la arqueología catalana, su perspectiva teórica y su influencia a largo plazo incluso tras su exilio.

\begin{abstract}
This article presents an intellectual profile of Pedro Bosch Gimpera. It reviews his academic training, the social and intellectual environment in which he grew up, his role in the institutionalization of Catalan archaeology, his theoretical outlook, and his long-term influence even after his exile.
\end{abstract}

Palabras clave: Historiografía de la arqueología; España; Catalanismo; Política y arqueología; Ideología y arqueología; Prehistoria; Pedro Bosch Gimpera; Institut d'Estudis Catalans; Adolf Schulten; Gustaf Kossinna; Tartesos.

Key words: History of Archaeology; Spain; Catalanism; Politics and Archaeology; Ideology and Archaeology; Prehistory; Pedro Bosch Gimpera; Institut d'Estudis Catalans; Adolf Schulten; Gustaf Kossinna; Tartesos.

(*) Instituto del Patrimonio Histórico Español (actual Instituto del Patrimonio Cultural de España). Ministerio de Educación Cultura y Deporte). C/ Pintor El Greco 4. Ciudad Universitaria. 28040 Madrid.

Recibido 1-II-2003; aceptado 11-IX-2014.

\section{PRESENTACIÓN DEL CONSEJO DE REDACCIÓN AL PRESENTE ARTÍCULO}

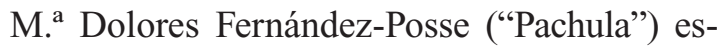
cribió este texto en febrero de 2003 como parte de la serie Cursos y Conferencias 4, "Historiografía de la Arqueología Española. Las personalidades", celebrada en el Museo de San Isidro (Madrid) ese año. El organizador del ciclo, D. Salvador Quero (Jefe de la División de Exposiciones y Difusión en el Ayuntamiento de Madrid y Conservador en Museos municipales) tenía previsto publicarlas siguiendo el formato de las del año 2001 (1). El retraso en la edición coincidió con los recortes presupuestarios debidos a la crisis, con una nueva política municipal sobre las publicaciones en línea y con la jubilación de Salvador Quero en 2014. Esas circunstancias llevaron al Museo a abandonar el proyecto.

El Consejo de Redacción de Trabajos de Prehistoria, del que Pachula fue vocal (2000-2007), conocía su contribución sobre Pedro Bosch Gimpera que consideraba de enorme actualidad e interés. El éxito en las gestiones con Javier Sánchez-Palencia para disponer del manuscrito y con el Museo de San Isidro para recabar la pertinente autorización (11-IX-2014) permite ahora publicar esta reflexión sobre la trayectoria de este Maestro catalán, cuyas responsabilidades excedieron el ámbito de la arqueología en un momento crítico de la Historia de España. Al hacerlo, rendimos homenaje a nuestra admirada y querida compañera a la vez que refor-

(1) http://www.madrid.es/UnidadWeb/Contenidos/Publicaciones/TemaCulturaYOcio/SanIsidro/HistArqueologia/cat.pdf (consulta 5-VIII-2014). 
zamos una de las líneas editoriales tradicionales en Trabajos de Prehistoria.

La tarea editorial ha consistido: en la organización del texto en secciones; en la incorporación del resumen y palabras clave, de notas y agradecimientos y en la revisión bibliográfica y tipográfica para adaptarlo a las normas de presentación de originales de la revista.

\section{INTRODUCCIÓN}

La invitación que amablemente me hizo en su momento Salvador Quero para hacer, dentro de este interesante ciclo de historiografía de la Arqueología española, una semblanza sobre Pedro Bosch Gimpera (Barcelona, 22 de marzo de 1891-Ciudad de México, 9 de octubre de 1974) es sin duda un encargo agradable. Se trata de una figura no sólo relevante en la historia de la disciplina, sino que ha suscitado siempre simpatías entre los arqueólogos. No en vano fue un personaje "progresista" que, además de ser un gran investigador, trabajó en la gestión de la arqueología pública, es decir, contribuyó a su institucionalización y su profesionalización. Además es un autor bastante bien documentado. Cuenta con textos autobiográficos, un biógrafo, el mejicano Juan Comas (1963, 1976), y numerosas referencias debidas a aquellos que se consideraron sus discípulos y se integraron en lo que ha sido reconocido, quizás con algo de optimismo y bastantes tópicos, como la Escuela de Barcelona. Por otra parte no se ha terminado de escribir sobre él. Sigue siendo glosado en vida y obra por autores como Jordi Cortadella (1988, 1991), atendido por investigadores jóvenes como Alfredo Mederos (1999) o citado por autoridades del prestigio de Colin Renfrew (1990).

Va a ser poco menos que imposible, con tantos datos a disposición, abarcar en una charla toda la figura de Bosch. Yo misma escribí hace unos años (Fernández-Posse 1998: 41-42) que había dos Bosch: uno para los investigadores que trabajan en Prehistoria reciente, que miran con agrado la evolución autóctona que propuso para algunas de las culturas peninsulares y que, por tanto, optara por posiciones contrarias a las formulaciones difusionistas y colonialistas que predominaron en la Prehistoria española hasta bien entrados los años
1980. El otro Bosch era el de los investigadores que trabajan sobre la Edad del Hierro que, tras décadas de matizar, o incluso de prescindir de sus oleadas de invasiones de gentes europeas, asisten en la actualidad a un resurgimiento de esos componentes étnicos, o por mejor decirlo, de esa lectura étnica de los complejos arqueológicos en la que, al igual que Bosch, se buscan las raíces históricas de la Península Ibérica. Pero además de esos dos Bosch hay muchos más: el becario, el docente, el traductor $-\mathrm{y}$, por tanto, el divulgador de teorías y conocimientos sobre la Antigüedad- el catedrático, el investigador, el director de museo, el político, el exiliado, etc. De esta forma me he visto obligada a elegir algunos de esos Bosch y, en consecuencia, a renunciar a otros; como también deberé detenerme sólo en algunos tramos de su extensa obra para caracterizar su pensamiento. Es evidente la imposibilidad de glosar en poco tiempo su figura y sus contribuciones. Mi justificación está en que, pese a las muchas anotaciones, propias y ajenas, antiguas o recientes que se disponen sobre Bosch, no deja de ser un investigador de historiografía complicada y también -es preciso decirlo-, en ocasiones llena de generalizaciones. Por otro lado, al componente ideológico y político de sus reconstrucciones históricas hay que sumar la utilización, muchas veces sesgada o dirigida, de su figura y su labor; y a ese doble condicionante ha de añadirse el de mi propia visión. Pero de una u otra forma este es "mi" Pedro Bosch Gimpera.

En primer lugar, examinaré dos de los factores que permiten entender su pensamiento arqueológico y su trayectoria vital: la formación recibida y el ambiente en que se desenvolvió en su juventud. Esos dos factores son en Bosch tan determinantes como en cualquier otro intelectual, pero en su caso llegan a ser complementarios, algo que no es tan corriente ni manifiesto en otros investigadores. Antes de nada quisiera subrayar esa circunstancia: Bosch fue el intelectual que necesitaba un ambiente concreto y supo actuar en consecuencia. Sólo así puede entenderse su precoz e irresistible promoción a una brillante carrera lo que, además, le proporciona una de sus características más interesantes: su representatividad. Esa cualidad que le dotó de un indudable papel protagonista en la arqueología española anterior a la Guerra Civil es precisamente la que trata de ser prolongada y aprovechada por su supuesta heredera, la Escuela de Barcelona. 


\section{PRIMERA JUVENTUD Y FORMACIÓN}

Los episodios de juventud de Bosch son muy conocidos y siguen siendo objeto de atención. Como ejemplo de ello podemos citar a Mederos (1999: 9), un autor igualmente joven, que sostiene que fue en ese periodo en el que el profesor catalán hizo sus aportaciones más significativas. Todos sabemos de sus estudios en el Instituto Balmes, sus cursos de idiomas, sus dos carreras universitarias -Derecho y Letras- en Barcelona y sus doctorados correspondientes en Madrid. También sabemos, con evidencia, que a los 20 años se consideraba un filólogo clásico. El propio Bosch (1980: 51) y también Luis Pericot (1963: XIX) han comentado bastante extensamente el desprecio o la indiferencia, cuando no la total inexistencia, de que eran objeto la Arqueología y la Prehistoria en el ambiente académico de ese momento. Esas explicaciones o comentarios, por más que sean anecdóticos, no sólo son inciertos sino que son interesados. Basta recordar que en 1905 comenzaban las excavaciones en Numancia, fecha en que los hermanos Henri y Louis Siret (Siret y Siret 1887) habían dado ya a conocer amplios repertorios de la Prehistoria del sureste y circulaban obras generales, como por ejemplo la de Émile Cartailhac (1886), sobre la Península Ibérica. En esos años, además, el Marqués de Cerralbo (2) y Juan Cabré (3) excavaban intensamente las necrópolis de la Meseta y sus trabajos comenzaban a ser apreciados en Europa. El patrimonio arqueológico iniciaba su institucionalización con la Ley de 1911 y la constitución de la Junta Nacional de Excavaciones y Antigüedades; y Ampurias, tan cercana a Barcelona, llevaba ya varias campañas de excavación.

Pero estamos precisamente en 1911 cuando, con recomendación de Francisco Giner de los Ríos, Bosch viaja a Berlín como becario, pensionado como se decía entonces, de la Junta de Ampliación de Estudios. Un destino que no era precisamente el más solicitado, pero que sí era

(2) Enrique Aguilera y Gamboa. Páginas de la Historia Patria por mis excavaciones arqueológicas, 1911. Texto mecanografiado inédito, VI Premio Martorell de arqueología española (23-IV- 1912) (http://museocerralbo.mcu.es/web/docs/ publicaciones/catalogosDeExposiciones/paginas_historia.pdf, consulta 12-IX-2014).

(3) Véase n. 2. el adecuado para el joven filólogo que queda allí a cargo de Ulrich von Wilamowitz-Moellendorff, el primero de sus tres profesores alemanes. Wilamowitz sabía tres cosas que no sabía Bosch. Primera, que era precisamente él quién había recomendado encarecidamente al emperador Guillermo II que otorgase una subvención a Adolf Schulten para excavar en España, y segunda, que conocía bien el ambiente catalanista donde se movía el nuevo becario. Sin embargo, el griego de Bosch (1980: 61) era insuficiente para seguir sus clases, como el mismo reconoció en más de una ocasión, y Wilamowitz -y esta es la tercera cosa que ignoraba Bosch-, que estaba muy interesado en las cerámicas ibéricas publicadas hacía unos años por Pierre Paris (1903-1904). Por ello le aconseja que estudie arqueología heládica, minoica y micénica, precisamente los círculos culturales con los que se relacionaban tales cerámicas catalanas y levantinas. Como vemos, de esta forma lo dirige con toda intención a su segundo profesor alemán, August Frickhenhaus, que estaba a cargo de un seminario de arqueología egea. Frickhenhaus estaba todavía más directamente interesado en la arqueología catalana. No en vano él mismo había estudiado, por encargo de la Junta de Museos de Barcelona, los vasos griegos de Ampurias en 1908, yacimiento que ya se estaba excavando, como hemos apuntado, bajo la dirección de Josep Puig i Cadafalch. El interés de este segundo profesor por esas cerámicas pintadas, supuestamente vinculadas a las egeas y que aparecían junto a las griegas que él había estudiado, es todavía más claro.

Es en el seminario de Frickhenhaus donde Bosch toma realmente contacto con la Arqueología, algo que se refleja en su correspondencia con el organismo patrocinador de su beca, la Junta de Ampliación de Estudios, donde comenta que dedica su tiempo a la Filología y la Arqueología por igual (Díaz Andreu 1995: 81). De hecho en ese seminario conocerá tanto los grandes yacimientos mediterráneos de la época (Troya, Tirinto, Knossos, etc.), que la memoria de la prórroga de su pensionado versará sobre Grecia y la civilización cretomicénica (Bosch 1914).

Para ese su segundo pensionado le aconsejan que asista a un curso práctico de Arqueología, es decir, de clasificación y catalogación de materiales, que impartía un conservador del Museum völkerkunde de Berlín, Hubert Schmidt, que será

Trab. Prehist., 72, N. ${ }^{\circ}$ 1, enero-junio 2015, pp. 8-21, ISSN: 0082-5638

doi: $10.3989 /$ tp. 2015.12141 
su tercer profesor alemán. Allí, como ayudante voluntario, Bosch trabaja con los materiales de la Troya de Schliemann y con los del propio Schmidt procedentes de Cucuteni. También este tercer profesor tenía sus motivos. Conocía bien la prehistoria peninsular sobre la que ya había publicado algunos trabajos (Schmidt 1915). De hecho Bosch es su anfitrión en un viaje a Cataluña que realiza en esos años. Le enseña la Colección Vidal, visitan Ampurias y le presenta a Puig i Cadafalch. Los intereses de Schmidt se centraban en realizar excavaciones en España donde veía grandes posibilidades para plantear relaciones y comparaciones como las que Siret y Cartailhac hacían entre los materiales a ambos lados del Mediterráneo, pero estas ambiciones nunca se cumplieron a causa de la Gran Guerra. Estos tres profesores alemanes fueron, en definitiva, quienes le descubrieron a Bosch la Prehistoria española además de considerarlo un contacto sumamente útil para temas que les interesaban personalmente.

Esa reorientación de la Filología clásica a la Arqueología -que algunos de sus biógrafos achacan a motivos casuales- ha sido planteada también como un cambio poco traumático e, incluso, nacido de la toma de conciencia, y disgusto consiguiente, por parte de Bosch al ver la Prehistoria española en manos extranjeras, atribuyéndole quizás una excesiva visión de futuro.

Independientemente de esas opiniones, creo que ese viraje tuvo entre otros muchos motivos unas razones decisivas y, como es habitual en la vida de casi todo el mundo, más accidentales y pragmáticas. Las vemos, por ejemplo, en el hecho de que Bosh aprovechara su beca berlinesa para preparar oposiciones al Cuerpo General de Archivos, Bibliotecas y Museos, para lo que forzosamente tenía que saber Numismática, Epigrafía y Arqueología, entre otras cosas; resultaba pues muy oportuno seguir algunos semestres en esas materias. Pero el episodio determinante que le avocó a la especialidad de Arqueología sucedió en el curso de esa visita a Puig i Cadafalch a la que he aludido anteriormente y que tuvo lugar al final de su primera estancia en Berlín. En esa ocasión Puig, como Vicepresidente del Institut d'Estudis Catalans, le ofreció la dirección de un futuro Servicio de Investigaciones Arqueológicas similar a los ya existentes de Arte o de Literatura. Pero se la ofreció con varias condiciones: tendría que compartir ese cargo con Josep Colominas, que sería director técnico; debía volver de Berlín y, sobre todo, tenía que completar su formación arqueológica e histórica. Y Bosch hace exactamente eso. Corta su beca de Filología para estudiar Historia, sección que, por otra parte, acaba de instituirse en la Universidad de Barcelona y que ofrece posibles plazas de profesor. Es evidente que la Arqueología, con esa entrada en la Universidad y el generoso ofrecimiento de Puig i Cadafalch, presentaba excelentes expectativas y hacen que Bosch se decida finalmente por ella. Sin embargo, como todos los autores que han escrito sobre él, no podemos menos que preguntarnos la razón de esa espléndida oferta a un jovencito de 20 años que no había excavado en su vida y todavía no había publicado nada. Sobre todo si tenemos en cuenta que la finalidad del Servicio ofrecido era potenciar las excavaciones y estudiar y publicar sus colecciones arqueológicas. Creo también que a Bosch debió sorprenderle el ofrecimiento tanto como a sus biógrafos.

La razón, con evidencia, no estaba en los conocimientos o experiencia de Bosch en arqueología catalana, ni siquiera en esas primeras y muy valoradas conexiones alemanas, no en vano Alemania era entonces la élite de la "academia" europea. La razón estaba en el ambiente, en el contexto intelectual y social al que Bosch pertenecía. $\mathrm{Y}$ no me refiero estrictamente a esa dimensión catalanista que siempre tuvo, sino que para ese catalanismo -no sólo intelectual, sino también político- era un hombre de confianza, lo que podría expresarse como "uno de los nuestros". Sobre este particular Cortadella (1991: 165) sugiere, como le contó Alberto Balil, que Bosch conocía a Joan Maragall -quizás más razonable sería pensar que Maragall conocía a Bosch-por haberle traducido algunos de los cantos homéricos para un proyecto que pone en evidencia la importancia que se le otorgaba a la Antigüedad clásica en ese ambiente catalanista de principios de siglo.

Volveremos más adelante sobre ese ambiente intelectual y político del que ya desde tan joven forma parte Bosch. Ahora lo que interesa es señalar que la dirección del Servei le pareció un ofrecimiento en firme y cursó de inmediato la carrera y el doctorado en Historia. La importancia de esa oportunidad queda muy bien reflejada en las propias notas autobiográficas de Bosch, sobre la que aporta además unas cuantas anécdotas. Más que ellas nos importan esa segunda tesis y 
algunos determinantes contactos e ideas que tuvo y recogió en Alemania antes de que la Guerra del 14 cortase su segunda estancia en Berlín. Ese doctorado, que defiende en 1913, se titula significativamente "El problema de la cerámica ibérica". Bosch la fecha -porque el problema a que hace referencia el título se centraba en el origen y cronología de esa cerámica- por debajo del siglo V a.C. y la considera indígena. Lo que no es poco teniendo en cuenta que Paris (1903) y Pijoan (1908: 262) la consideraban del siglo XII a.C. y emparentada con lo micénico. Aunque también había otras opiniones como la de Siret (1907) que la creía púnica o la de José Ramón Mélida Alinari (1883) -que fue precisamente el director de la tesis de Bosch- que la pensaba celtibérica.

Habla de ese trabajo con Schulten en Erlangen durante una visita que le hace en la segunda etapa de su beca alemana; habla de esa cerámica pero también de Etnología antigua. Es decir, fue Schulten quien despertó su interés por el que terminaría siendo el tema central de su investigación -la paleoetnología o la formación de los pueblos-, por más que, contrariamente a lo que suelen comentar algunos autores, nunca fue su profesor. A raíz de este contacto, todavía en 1914, Bosch comienza a traducir algunos de los libros de Schulten (p. ej., Schulten 1920) e inicia una relación que, desde el punto de vista intelectual, fue importantísima.

Pero, por decisiva que sea, no es ésta la única visita o viaje. Bosch no fue un becario sedentario y de biblioteca. Antes al contrario, tuvo una beca bastante azarosa. Viajó a muchas capitales europeas y vio muchos museos, pero sobre todo en esta segunda estancia fue introduciéndose en algunas sociedades o asociaciones berlinesas de la disciplina. En el marco de esa apertura de relaciones es admitido en un seminario de Prehistoria que dirigía Kossinna. Uno no puede menos que preguntarse si fue consejo de Schulten, porque en aquel momento Kossinna -que estaba en la cincuentena- era un prestigioso y famoso profesor, una verdadera figura para el país al que prestaba las bases históricas que hacían de la Arqueología una ciencia nacional pangermana, muy al contrario que su tercer profesor alemán, el conservador de museos Schmidt. Éste trabajaba en el ámbito opuesto -el mediterráneo- que Kossinna intencionadamente ignoraba. Mederos (1999: 18) relata bien esos enfrentamientos o diferencias académicas. Sea como sea, fue este famoso profesor -más que Schulten- quien le hizo ver claras a Bosch las posibilidades de la Arqueología, ya que la teoría y la metodología de aquellas clases van a estar presentes en toda su obra hasta el final: el idealismo histórico, los grupos culturales con contenido étnico, su fijación por medio de objetos seleccionados como marcadores culturales y, más que la difusión cultural, las invasiones, las masivas emigraciones de pueblos centroeuropeos, generalmente más avanzados y desde un origen concreto, que podían contrastarse mediante los citados marcadores. Bosch también aprendió que las secuencias arqueológicas se pueden convertir en desarrollos propios de etnias concretas. De hecho lo reconoce así -aunque lo dice a posterioriadjetivándolo como un gran profesor y maestro: "aprendí qué eran los círculos de cultura y su relación con los pueblos" (Bosch 1980: 65).

En definitiva, Bosch se trajo de Alemania -y en ese sentido era razonable que alcanzara ese protagonismo, ese carácter de hombre providencial al que antes aludimos- las ideas, los conceptos que necesitaba la construcción de una arqueología propia de su ambiente. En ese sentido no pudo ser más oportuno. Sobre todo, ese particularismo que, unido al idealismo histórico propio de su época, permite establecer una prolongada continuidad cultural, de forma que un pueblo puede mantener su esencia racial, su "alma permanente" a lo largo de la Historia. Algo que casaba muy bien con el catalanismo, con el nacionalismo catalán. Todo ello es, en cierto modo, y si se me permite la expresión, "puro" Kossinna, autor de mala fama -bien merecida si se atiende a la nefasta proyección que tuvo su pensamiento en la formación y establecimiento del nazismo-, del que suele admitirse la influencia que sus ideas tuvieron en Bosch aunque rodeándola de reservas $\mathrm{y}$ aclaraciones a mi juicio innecesarias. Porque podemos recordar que Childe, un genio fuera de toda sospecha, entendía la Prehistoria en términos de difusionismo y de círculos culturales y eso no le impidió ser un materialista histórico; algo que, por más que consideremos a Bosch una figura progresista, y no hay duda que por ello sufrió el exilio del franquismo para el que era simplemente un "rojo", jamás profesó.

Aunque expuesto de forma breve, con lo anterior podemos hacernos una idea de lo que aportaba Bosch como producto de su etapa alemana. Ahora, también de forma obligadamente

Trab. Prehist., 72, N. ${ }^{\circ}$ 1, enero-junio 2015, pp. 8-21, ISSN: 0082-5638

doi: $10.3989 /$ tp.2015.12141 
esquemática, debemos atender al otro factor: el "ambiente", el medio social e intelectual al que aportó ese bagaje.

\section{EL AMBIENTE SOCIAL E INTELECTUAL DE SU JUVENTUD}

El contexto intelectual, social, cultural y político de Bosch, con el que tan bien casaba lo aprendido en Alemania, era el catalanismo conservador. No en vano en ese rápido repaso sobre su periodo de primera juventud y formación han aparecido los nombres de dos de sus dirigentes más señalados: Maragall y Puig i Cadafalch. Este nacionalismo conservador era, en esos años juveniles de Bosch, un movimiento y partido político perfectamente caracterizado y establecido, de composición muy homogénea; tanto como para detentar hegemónicamente el poder durante las primeras décadas del siglo XX. Esto es, desde la creación de la Lliga Regionalista de Prat de la Riba, en 1901, hasta la Dictadura de Primo de Rivera (1923-1930). Esta Lliga Regionalista, como partido político que arrasó en las elecciones de ese primer año del siglo, era el resultado final de la depuración de un movimiento más amplio y difuso que se desarrolló sobre todo en la segunda mitad del XIX: un "sentimiento" colectivo de recuperación de la identidad nacional. Se trata de la lengua y la cultura catalana (lo que se conoce como la Renaixença), pero también es mucho más. Es el teatro popular de Federico Soler, la proliferación de periódicos, el movimiento excursionista con la exaltación del conocimiento y valoración de un arte, una historia y un folclore propios. Son las numerosas formaciones de canto coral, los orfeones que recuperan la canción tradicional, son las también numerosas escuelas de sardana, etc; todo un despliegue de asociacionismo como escuela de patriotismo y afirmación de la identidad. Y ahí está la diferencia: fue la sociedad civil, las bases populares de la sociedad catalana, la verdadera protagonista de esta recuperación de una conciencia nacional, obligadamente perdida desde el siglo XVIII. Un componente popular que vemos igualmente en otros nacionalismos europeos del momento. A ese contexto general nacionalista pertenecía la familia de Bosch, o al menos sus padres, comerciantes que dieron a su hijo único, según nos relata el mismo, una educación propicia para llegar a ese medio burgués $\mathrm{y}$ culto donde gustaban ver integrarse al joven intelectual de la familia y donde pronto comenzó a desenvolverse y a escalar puestos.

Pero es el catalanismo político, y su decisivo y marcado componente federalista construido por Pi i Margall, quién refuerza y orienta esa mentalidad general nacionalista, ese sentimiento de identidad propia. Bosch se alinea en aquel de tendencia más conservadora que es derrotado, en el seno del Centre Catalán, por Valentí Almirall en 1887. Entre estos conservadores escindidos está un todavía universitario Puig i Cadafalch que pertenecerá sucesivamente a la Lliga de Catalunya, la Unió Catalanista y la Lliga Regionalista y a sus instituciones, como Solidaritat Catalana o la Mancomunidad de Catalunya, desde donde, ya bien situado políticamente, ofrece en 1913 a Bosch la dirección del Servei de Arqueología del Institut d'Estudis Catalans, del que, como dijimos, era vicepresidente. La ideología y aspiraciones de esta formación, bien reflejadas en el texto de las Bases de Manresa de 1892 y en las publicaciones de su máximo dirigente Prat de la Riba, sobre todo en su libro La nacionalitat catalana, y que nos interesan hoy con referencia a la construcción arqueológica de Bosch, es la perfecta diferencia que se establece entre los conceptos de "nación" y "estado", siendo el primero un "producto natural", exista, y se la reconozca como tal, o no. Es clara la influencia en esta idea del idealismo alemán y del positivismo tradicional. No hay en ella un planteamiento independentista, pero sí un fuerte contenido federalista. La soberanía pretendida es sólo en cuestiones de orden interno. También interesa remarcar hoy quienes eran los componentes de esta formación política: propietarios, comerciantes, fabricantes, industriales, artistas y profesiones liberales. Es un partido, por lo tanto, y unas fuertes instituciones, de las que es el mejor ejemplo la Mancomunidad de Cataluña fundada en 1907, de caracterización claramente conservadora y burguesa. Como es sabido, la izquierda del catalanismo político tardó años en presentar una alternativa creíble a esta facción conservadora, Esquerra Republicana de Cataluña, que accede al poder en la República de 1931.

Bosch queda así situado en ese ambiente intelectual, pero también político, que, además, se refleja claramente en algunas de las anécdotas 
que el mismo relata en sus textos autobiográficos cuando comenta que la primera vez que oyó hablar de cerámica ibérica fue en una conferencia de Pierre Paris organizada, precisamente, por Puig i Cadafalch en 1909 o 1910. Es evidente que en esas fechas no le interesaban todavía ni esa ni ningún otro tipo de cerámica. Estaba allí porque pertenecía a ese ambiente, al igual que en otros actos similares que se celebraban en tales instituciones (como las Academias, tipo la de las Bones Lletres, el Ateneo y sobre todo Estudis Universitaris Catalans) que proliferaban en la Barcelona de principios del siglo XX y cuyos programas reflejan claramente su elevado nivel. Las gentes que constituían esa élite intelectual y cultural, relacionadas con la Lliga Regionalista en el poder, y entre las que menudeaban historiadores, juristas, filólogos, etc., además de políticos, se servían de ellas como trampolín para la vida pública.

En Cataluña la Arqueología se hacía precisamente en ese tipo de organismos y no, como podría pensarse, en la Universidad. La expresión escrita de los trabajos era ya el Anuari del Institut d'Estudis Catalans y funcionaba muy bien la Junta de Museos de Barcelona, patrocinada conjuntamente por la Diputación y el Ayuntamiento, cuya máxima realización eran las excavaciones en Ampurias.

Bosch pertenecía, pues, a ese ambiente y siguió en él hasta su exilio. Un ambiente, se podrá objetar, similar a otros muchos que se dieron en Europa en el cambio de siglo. Pero en Cataluña había esa clara diferencia ya anotada: un mayor peso del componente político que supera con creces esa "sensibilidad catalanista" que le atribuyen, algo eufemísticamente, algunos autores. En mi opinión era consciente de su compromiso desde el principio (aunque no firmase Bosch i Gimpera) $\mathrm{y}$, por ello precisamente, serán esas instituciones de marcado carácter nacionalista y poseedoras de un proyecto de futuro en el que la valoración del pasado podía cumplir un importante papel, quienes le van a prestar todo el apoyo. No en vano ese interés, más o menos político y también más o menos retórico, por el pasado estaba ya en el Romanticismo tardío o crepuscular del que se nutrieron los movimientos resurgistas y todos los nacionalismos del XIX y aún del XX. Entre ellos estaba el catalanismo político que, además de esa importante base popular a la que he hecho referencia, tenía otra característica que hoy nos interesa particularmente porque es casi un paradigma arqueológico en Bosch. Es ese componente clásico, representado en esos cantos homéricos que traduce y versifica Maragall o en las mismas excavaciones en Ampurias, que se integraba en la tradición indígena vernácula en una dialéctica, bien aplicada por Bosch al registro arqueológico, de influjos externos de carácter civilizador que van a aparecer siempre en sus reconstrucciones históricas.

\section{LA INSTITUCIONALIZACIÓN DE LA ARQUEOLOGÍA CATALANA}

El resultado de todos estos factores, su particular formación y ese característico ambiente catalanista, a los que evidentemente hay que añadir su propia valía y la tenacidad que el mismo se atribuye como un rasgo distintivo de su carácter (Bosch 1980: 189), es su irresistible ascensión que, con el fuerte apoyo institucional ya mencionado, hace que en escasos años y aún siendo muy joven acapare numerosos puestos y representaciones. De esta manera, recién llegado en 1914 a Barcelona y tras realizar, ese mismo verano, trabajos arqueológicos, sus primeros trabajos de campo, en Aragón y en Ampurias, tal y como no esperaba menos de él Puig i Cadafalch, se incorpora a la prometida dirección del nuevo Servei de Investigaciones Arqueológicas del Institut d'Estudis Catalans. Estamos en 1915 y tiene 24 años. En dicho Servei cuenta con dos ayudantes, Durán y Colominas, y comienza a impartir un curso de Arqueología catalana. Se prepara, además, para la cátedra de esa nueva sección de Historia de la Universidad de Barcelona, donde en 1916 da sus primeras clases en Historia Universal Antigua y Media.

Ese joven profesor, con indudable éxito entre sus alumnos, recluta para el Servei a tres jóvenes de 18 años que llenarán varios decenios de la Prehistoria española: Luis Pericot, Josep de C. Serra i Ràfols y Alberto del Castillo. El primero de ellos, que guarda un recuerdo hagiográfico de Bosch como profesor, relata, sentimental, esos primeros momentos del Servei y el entusiasmo que le produjo la primera conferencia de su maestro (Pericot 1963: xxi.xxiii). Pero es evidente que lo interesante es lo que comienzan a hacer allí y que

Trab. Prehist., 72, N. ${ }^{\circ}$ 1, enero-junio 2015, pp. 8-21, ISSN: 0082-5638

doi: $10.3989 /$ tp. 2015.12141 
no es exclusivamente, aunque también la hace, arqueología catalana. Realizan amplias revisiones bibliográficas en una buena parte encaminadas a confeccionar una cartografía de hallazgos y monumentos prehistóricos españoles y recopilan material tanto documental como gráfico para una España Histórico-Artística (Mederos 1999: 21). Todo ello con vistas a la Exposición Universal de Barcelona que se celebraría, finalmente en el año 1929. Este trabajo les obliga a revisar y construir la secuencia prehistórica de la Península Ibérica. Quien revisa los megalitos es el joven Pericot, quien el Neolítico es Serra Rafols y Castillo se ocupa del campaniforme. Son estos años, de 1915 a 1920, cuando Bosch queda inmerso en una realidad arqueológica a escala global. En ella está la base material de su Etnología, su obra fundamental (Bosch 1932).

Como es sabido tuvo una espléndida carrera académica. Durante toda la década de los 1930 ocupó cargos en la Universidad de la que fue Rector, colaborando con la Generalitat en sucesivas reformas educativas. Pero donde esa carrera es prodigiosa es en el resto de las instituciones y organismos relacionados con la Arqueología y el patrimonio arqueológico. Fue desde el 1923 al 1932 Director del Museo de Arqueología, al que dotó por ejemplo de una biblioteca, y Secretario del Patronato para las excavaciones en Ampurias. Fue también Comisario de Museos, Director del Seminario de Prehistoria de la Universidad, Vicepresidente de L'Associació Catalana d'Antropología, Etnografía i Prehistoria y, tras el Estatuto de Autonomía de 1933, organiza y dirige la política arqueológica de la Generalitat y adopta las medidas de protección legislativas y físicas del Patrimonio Catalán.

Y podríamos seguir. Aunque prefiero fijar la atención en dos cosas. La primera es que, en la etapa autonómica de la República, la Generalitat demuestra en las gentes elegidas para gestionar la arqueología, incluido Bosch, la sintonía política con el Institut d'Estudis Catalans. La segunda, que se ha señalado en más de una ocasión, es que Bosch llegó a dirigir y a coordinar todas las instituciones vinculadas al tratamiento del patrimonio arqueológico. Yo diría más, cubrió todas las dimensiones de la arqueología oficial: la investigación, la conservación y difusión desde los museos, y su tutela y gestión desde los cargos políticos, amén de su enseñanza desde la Uni- versidad. Su protagonismo, de hombre proverbial, que señalábamos al principio como una de sus características, estaba justificado. Aunque aquella época, como durante las décadas posteriores del franquismo, era proclive a estos acaparamientos de puestos en torno a una actividad, todos recordamos al Profesor Almagro Basch, por ejemplo.

\section{TEORÍA, METODOLOGÍA E IDEOLOGÍA DE BOSCH GIMPERA}

Ahora me voy a permitir un pequeño salto hacia atrás hasta aquellos primeros años de los seminarios en el Servei, para tratar un tema al que ya he aludido: la Escuela de Barcelona que ha sido siempre considerada como una herencia directa de Bosch y uno de los pocos fenómenos de ese tipo que se han dado en la Prehistoria española.

Uno de aquellos jóvenes primeros colaboradores de Bosch, tanto en la Universidad como en el Instituto, Luis Pericot, la define o caracteriza como aquella que revaloriza los aspectos históricos de los temas arqueológicos, que procede con ambición y prudencia en las hipótesis, que muestra preferencia para la explicación del cambio cultural más por la difusión que por la convergencia y que está dotada de cierto matiz panmediterráneo (Comas 1976: 37). Dicha definición podemos completarla con otros comentarios que proporciona el mismo Pericot (1963: XXIV) sobre lo que llama el "método prusiano", implantado por Bosch en el Servei: gran detalle en los diarios de excavación e inventarios, así como otra serie de cuestiones que, ya no Pericot, sino otros de los muchos autores que han tratado sobre su pensamiento mencionan. Ese método prusiano no es otra cosa que el afán catalogador y tipologista en que desemboca siempre el positivismo más plano, aunque algunos miembros de su supuesta escuela no fueran precisamente un modelo de rigor y llegaran a defender algunas cuestiones con un más que precario apoyo empírico. Positivismo propio de la Arqueología española durante el franquismo, donde los datos no sólo son lo importante sino que terminan por convertirse en el único objetivo de la investigación. De igual manera que el concepto de círculo cultural que Bosch importa de Alemania desemboca en el normativismo más o menos acusado de la tradición histórico cultural 
que ha dominado la Prehistoria española durante décadas. Lo mismo sucede con el "invasionismo", que no es otra cosa que un difusionismo exacerbado. Todo lo anterior combinado, pese a lo paradójico de la combinación, con repuntes de idealismo y principio de autoridad. Ese es, a grandes rasgos, el único soporte teórico que funciona en España en las décadas centrales del siglo XX. Con esta simplificación de la arqueología franquista lo que quiero indicar es que si las características de la Escuela de Barcelona son las que Pericot definió y sintetizó para la posteridad, a dicha Escuela pertenecieron, o pertenecimos, la gran mayoría de los investigadores españoles hasta no hace muchos años.

Incluso en esa visión simplificada se dejan ver las diferencias en los esquemas conceptuales que separan a Bosch de los que se titularon de su escuela y de la Arqueología de casi todo el siglo $\mathrm{XX}$. Sin embargo creo que puede afirmarse que Bosch determina de forma fehaciente la investigación arqueológica hasta el final del siglo pasado. Por otro lado, esas diferencias son más marcadas entre Bosch y los que con él se alinearon en el sentido de que los segundos no llevaron ni su ideario ni su metodología, es decir, su construcción arqueológica, a sus últimas consecuencias. Por el contrario, desproveyeron a su pensamiento de lo que tenía de original y olvidaron sus fines. Desde ese punto de vista tienen razón aquellos autores que opinan que la obra de Bosch culmina y termina en ese libro de 1932 Etnología de la Península Ibérica o en su versión mejicana de 1945 sobre La formación de los pueblos de España.

En esos libros y en el conjunto de su obra están presentes dos componentes teórico-metodológicos, señalados por todos los autores que han escrito sobre él, pero que quedan bien formalizados tanto en Cortadella (1988) como en Martínez Navarrete (1989). De un lado, el empirismo tal y como había sido desarrollado en Centroeuropa durante el XIX y, de otro, los esquemas etnológicos de la escuela histórico-cutural en su interpretación más alemana. Hay que añadir un tercer elemento que es su claro encuadre político en un catalanismo consolidado y conservador y de no menos claro corte federal. Pero esos tres componentes no están siempre presentes con la misma intensidad ni en la misma proporción. De forma que cuando se analiza a Bosch como primer sintetizador de la Prehistoria peninsular-que lo fue-se puede afirmar, como lo hace Martínez Navarrete (1989: 251), que es un buen ejemplo de la "visión normativista de la cultura"; e incluso observar en su discurso repuntes evolucionistas (Pasamar 1991: 308) o, por lo menos, no-difusionistas para explicar algunos cambios en el registro prehistórico. Pero cuando habla de pueblos prerromanos, ese registro empírico le importa relativamente mucho menos (Fernández-Posse 1998: 44-45), y es precisamente en ese último milenio antes del cambio de Era, entre pueblos de nombres citados por las fuentes antiguas, en el que Bosch parece desenvolverse con mayor gusto. De hecho, con excepción de un trabajo sobre la Cultura de Almería para la revista Pyrenae de 1969, es sobre lo que continuó escribiendo hasta el final de su vida. Sin embargo, y ahí está la cuestión, Bosch "tenía" que tratar todo el pasado por dos razones: la primera es que un Maestro que, como él llegó a serlo muy pronto, debía obligatoriamente hacer una obra de síntesis y contenido general, fuera sólo sobre su país o de toda Europa. Y eso pudo hacerlo Bosch, también muy pronto, porque en el propio Servei del Institut se había actualizado el registro de las principales manifestaciones culturales peninsulares. En segundo lugar, porque para hablar de "pueblos" era necesario remontarse a los primeros fondos étnicos, es decir a la Prehistoria reciente. En una palabra, la Cultura de Almería era el lógico punto de inicio para Bosch al igual que la cerámica de bandas y cordada era el de Kossinna. Este hilo del presente que lleva al pasado más remoto es el que conforma el componente más determinante de su pensamiento: su idealismo histórico. Los "pueblos" de España se conforman en ese pasado remoto. Y todos ellos dejan leer su "alma permanente" a través de su historia. Esto que más que un enfoque es una doctrina, fue común en la Europa de su época y su producto fue esa revalorización y reconocimiento de un pasado propio que, a otra escala y camuflado de positivismo ingenuo, falsamente apolítico en los trabajos más técnicos y patente en las obras de carácter más divulgativo, sobrevive ejemplarmente en el franquismo como intuye claramente Gilman (1988, 1995). De hecho, hace pensar a autores como Cortadella (1988) o García Quintela (1990) que la imagen de España de Bosch -donde sus conjuntos regionales, sus particularismos históricos, se corresponden con la posterior distribución de los reinos medievales y con la conformación de

Trab. Prehist., 72, N. ${ }^{\circ}$ 1, enero-junio 2015, pp. 8-21, ISSN: 0082-5638

doi: $10.3989 /$ tp. 2015.12141 
la España contemporánea- tiene el problema de coincidir conceptualmente con la del franquismo, dando la impresión que se trata solamente de una cuestión de "escala".

Para comprender esa visión histórica de España en Bosch, o mejor sería decir su "idea" de España, hemos de tener en cuenta su "esencialismo", es decir, su creencia en la permanencia a lo largo de la Historia de unos valores esenciales portados por los diversos pueblos hasta el siglo $\mathrm{XX}$. Algo que va más allá de ese "particularismo histórico" que suelen atribuirle y que responde, evidentemente, a una concepción de la Historia siempre ligada a la búsqueda de una respuesta a un problema de identidad colectiva, sea mayor o menor su contenido político o de clase. Un buen ejemplo de ello lo encontramos en su visión de la conquista romana. Los pueblos prerromanos que estaban ya estructurados como "naciones", en el sentido que le dio el catalanismo de principios del siglo pasado, reaparecen casi intactos y en su misma diversidad tras el largo periodo que la Península Ibérica formó parte del Imperio Romano. Y eso sucede, igualmente, con otras interrupciones -interferencias históricas las denomina Cortadella (1988: 19)- como pueden ser los visigodos, los árabes y, en el caso de Cataluña, los Borbones. Esa idea de una romanización de baja intensidad, minimizada, es muy propia de ese esencialismo racial de Bosch, por más que se mantuviera en autores franquistas y esté también presente en la visión indigenista con que a veces se aborda el estudio de las culturas prerromanas -particularmente las del Norte- en la actualidad.

En ese esquema boschiano de la Historia de España no está, por lo tanto, sólo la idea de esa diversidad ancestral y permanente y el concepto de "nación" de Prat de la Riba, sino que hay otro planteamiento más profundo. Siempre se conjugan dos elementos contrapuestos. Uno es siempre indígena, el de contenido racial, y otro exterior. Y esto que tiene mucho de obviedad cuando se habla de tiempos históricos no lo es para la Antigüedad, es decir para esa formación de los pueblos de España que es el tema central de su investigación. Lo podemos ver en uno de los episodios históricos más atendidos y controvertidos de la investigación de su época: Tartesos. Y hablar del Tartesos de esa época es volver a hablar de Schulten.

Ya hemos aludido a ese primer contacto entre ambos y cómo Bosch se encarga de traducir algunas de sus obras. Traduce primero Hispania -donde incluye un apéndice sobre la arqueología de los pueblos prerromanos-y luego, desde 1922, las Fontes Hispanie Antiquae (Schulten y Bosch Gimpera 1922) que serán los textos clásicos que utilizará Bosch a lo largo de su obra, y además, en el convencimiento que las fuentes literarias permiten una reconstrucción histórica que puede completarse con el registro arqueológico (Fernandez-Posse 1998: 44). Por otro lado, ambos autores compartían una matriz historicista e incluso cierta proclividad a creer en la legitimidad, para aquellos periodos que poseen tales fuentes literarias o etnofilológicas o lingüísticas, de que fueran la base del discurso histórico. Pese a que la construcción schultiana se adoba con mayores dosis de exaltación de un sistema de valores permanentes y de juicios de valor (Plácido 1991: 227), es esta visión de las formaciones sociales y étnicas antiguas la que hizo ya entonces comentar a Ortega y Gasset que Bosch no era aburrido, evidentemente en comparación a otros colegas arqueólogos más apegados a los datos. Pero esta relación SchultenBosch dio lugar a una circunstancia cuyas secuelas en la investigación sobre Tartesos se señala en la reciente y brillante tesis doctoral de Álvarez Martí-Aguilar (4), en la que se desarrolla la imagen de la cuestión tartésica en la historiografía española. Este joven historiógrafo remarca, en efecto, como Schulten debe a Bosch el reconocimiento académico de su concepto de Tartesos. Acepta su carácter indígena, su consideración de cultura "superior", su importancia y focalidad en el desarrollo de la protohistoria peninsular y sobre todo valida ante la comunidad científica la Ora marítima de Avieno como documento clave para su estudio. Lo hace precisamente en la Revista de Occidente que dirigía Ortega (Bosch 1925, 1928, 1929). Este respaldo hace que sea la imagen del Tartesos de Schulten la que termina por fijarse en las obras generales durante décadas (5). Paradójicamente, la visión tartésica de Bosch era bien diferente de esta más popular schultiana. No sólo comienza recortando los excesos del alemán sino que terminará siéndole antitética. Y no tanto por la

(4) M. Álvarez Martí-Aguilar. La imagen de Tartesos en la historiografia española (siglos XVI-XX). Tesis Doctoral. Universidad de Málaga, 2000. Fernández-Posse manejó el texto en prensa. Se publicó años mas tarde (Álvarez Martí-Aguilar 2005).

(5) Véase n. 4, p. 284. 
cronología, más razonable y basada en el registro arqueológico, que situaba en el VII a. C., sino por la propia localización de la supuesta capital que, desde la Isla de Saltés, trasladaba al interior del valle del Guadalquivir donde los trabajos de Bonsor la arropaban en una realidad arqueológica (Bosch 1928: 336-337). En definitiva, privaba al Tartesos de Schulten de todos los elementos legendarios y románticos y, sobre todo, de las posibilidades prefenicias o precoloniales que tanto complacían a la ideología del profesor alemán. Todo lo que rechaza Bosch lo hace, y esto es lo interesante, por falta de pruebas arqueológicas a las que califica en alguna ocasión de las más objetivas (Bosch 1929: 75). Eso no impide que lo siga considerando un reino indígena peninsular en un apriorismo ya fijado con anterioridad a Schulten y que permite vincularlo a lo fenicio.

Pero lo interesante de toda esta operación de desmontaje realizada por Bosch en el curso de varios años, todo hay que decirlo, es señalar que mientras Schulten quería un "imperio occidental", es decir, europeo, del que alardear frente a las clásicas civilizaciones orientales y donde los púnicos no tenían mucho que añadir, el Tartesos de Bosch -más cercano en el tiempo y siempre en relación con las alteraciones provocadas por sus oleadas célticas- es una "confederación" de pueblos, algunos de ellos anteriores a la Edad del Bronce, formada en el siglo VI según las informaciones de la Ora Maritima (Bosch 1945: 157148). Las palabras claves, en esta contraposición que realiza Álvarez-Martí-Aguilar (6), entre el autor "alemán" y el "catalán" serían "imperio" y "confederación" para sus respectivos Tartesos.

La visión del Tartesos de Bosch no por más razonable o más arqueológica deja de ser un buen ejemplo de ese historicismo esencialista que antes le atribuía. Es más, el elemento de influencia exterior, pese a poder serlo, tampoco era fenicio. En este caso se trata de griegos, clásicos y refinados, que llegan a una solución de compromiso con los cartagineses (Bosch 1945: 157). Por otro lado, estos tartesios le servían a Bosch para otra cuestión: demostrar que tenían una organización social compleja, donde encuadraba a monarcas, aristocracias, pueblo y esclavos, que contrastaba con la que poseían los íberos -a los que compara

(6) Véase n. 4, p. 284 y ss. con los bereberes- que conservaba en su mayor primitivismo esencias democráticas. De esta manera las poblaciones del litoral levantino eran independientes e igualitarias aunque proclives a formar federaciones ocasionales. Es claro que el vacío arqueológico para plantear estas cuestiones era el mismo para ambos autores y las informaciones de la Ora Maritima tan ambiguas como lo son ahora, pero no es menos cierto que, como dice Álvarez Martí-Aguilar (7), los valores esenciales de los indígenas íberos se plantean como precursores de "lo catalán". Los tartésicos con esa estructura monárquica y autoritaria quedan al margen de esos valores esenciales ibéricos.

Con este ejemplo vemos como esa singular psicología de los pueblos, por utilizar la expresión de Peiró y Pasamar (1990: 29), está tanto en el historicismo narrativo de Schulten, y es un claro subtexto en las historias oficiales del franquismo, como en la obra de Bosch. Por ejemplo, la predisposición de algunos pueblos al heroísmo y a la resistencia al invasor que tanto gustaba a un romántico tardío como Schulten y a las más retóricas historias de la dictadura franquista. Pero también la predisposición de los íberos, considerados como unos catalanes atemporales, a la democracia igualitaria propuesta por Bosch no deja de ser una idealización de exactamente el mismo nivel (8). Por más que estos días la democracia tenga, en nuestra escala de valores, mucho más crédito que la guerra.

Tras este tema de íberos que tan bien expresa el pensamiento arqueológico de Bosch y para completar eso que hemos llamado su idea de España, quizás resulte práctico aludir a lo que fue una de sus últimas manifestaciones arqueológicas antes del exilio. Se llama significativamente Espanya y fue su discurso para la inauguración del curso 1937 en la Universidad de Valencia. Hemos pues de imaginarnos las circunstancias y la intención de este texto, en plena Guerra. En él sintetiza lo que en su Etnología proponía de forma más argumentada pero también más confusa: un modelo federal $-\mathrm{y}$ por lo tanto contrario al dogma "ortodoxo" de la unidad de España- que muestra su fuerza en el renacer de su complejidad una y otra vez, porque sus unidades étnicas se recomponen tras cada episodio protagonizado por

(7) Véase n. 4, p. 289

(8) Véase n. 4, p. 92.

Trab. Prehist., 72, N. ${ }^{\circ}$ 1, enero-junio 2015, pp. 8-21, ISSN: 0082-5638

doi: $10.3989 /$ tp. 2015.12141 
un componente de influencia o dominio exterior. Complejidad que se convierte en atributo eterno y tema central del discurso histórico de lo que puede ser considerado su "testamento" en el que la correlación de los grupos prerromanos y primeros reinos cristianos es tan directa como, por ejemplo, la que puede establecerse entre tartesios y reinos taifas y de esta forma hasta los pueblos modernos.

\section{EPÍLOGO: DEL EXILIO A LA ACTUALIDAD}

Pero volviendo otra vez a su biografía diremos que tras esos intensísimos años de producción bibliográfica pero también y sobre todo de presencia y acción permanente, de capitalización de la Arqueología, Bosch, como tantos otros españoles, ha de exiliarse. Todos sabemos de sus estancias en Oxford, su puesto de Director de Filosofía y Humanidades de la UNESCO en París, entre 1948 y 1952, y sus contactos con colegas en algunos encuentros y seminarios; pero finalmente recala en Méjico y comienza en España su rápida transformación en una figura del pasado, porque pese a esa presencia permanente en la mente de los arqueólogos españoles de postguerra que suele atribuírsele, lo hace ya a la manera de los autores desaparecidos. Debido en parte a que se trata de un periodo de reconstrucción de las instituciones en cuyo marco se desarrollaba la Arqueología donde, además, se lucha por su control. Durante esos años confusos Bosch es perfectamente asimilado, por más que de los componentes metodológicos de su trabajo se prime aquello que sea más conveniente y su idealismo histórico se haga o más ambigüo o más retórico. Pero está claro que el panceltismo europeista de Martínez Santa Olalla (1946) sólo fue posible gracias a las incontables páginas que Bosch había escrito sobre movimientos de pueblos, sobre las sucesivas oleadas de grandes masas de celtas que, como el mismo admite en las conclusiones de El poblamiento antiguo y la formación de los pueblos de España, casi consiguen dar un carácter general a toda la península, por más que no llegaran a unificar la población. En esta "dominación" céltica, Bosch no sólo permite supervivencias y grupos indígenas intactos sino que considera que alcanza de forma diferente al cada vez más complejo conglomerado de etnias preexistente. Es fácil sobre los detalles de este esquema general y disponiendo de casi un milenio para fijar la multiforme sedimentación, por decirlo con típicas expresiones boschianas, primar las intensidades de unos u otros grupos étnicos, sobre todo cuando algunos, como los celtíberos, se fijaban por la Arqueología y siempre en relación a los íberos, otros, como los vascos, por la Lingüística, y la gran mayoría, por las fuentes antiguas. Además el propio Bosch modificó muchas veces su esquema, lo que permitió a Mata Carriazo (1947) ironizar sobre ello en la Historia de España que podemos calificar de oficial en la postguerra, la dirigida por Menéndez Pidal, cuyo tomo I ve la luz en 1947, o a Pericot (1976: 25) comentar de forma algo cándida que la tendencia de Bosch por perseguir las raíces remotas de los pueblos con nombre histórico duró hasta su muerte.

De una u otra forma Bosch está en el fondo de todo lo que se escribió sobre pueblos prerromanos hasta bastante avanzado el siglo XX, cualquiera que fuera el enfoque o la ideología del autor. Basta citar a autores tan diferentes como Caro Baroja (1946), García y Bellido (1952) o Maluquer de Motes (1955). Pero quiero terminar enumerando dos de sus planteamientos, casi paradigmas, que quedaron integrados en toda la investigación posterior. La primera es esa simplificada imagen de las dos Españas que posibilita tratarlas como dos grandes unidades que, de forma totalmente antiarqueológica, permiten hablar de rasgos y caracteres culturales contrapuestos: la céltica y la íbera. Aunque esa simplificación proviene de la tradición histórica multisecular, anterior a Bosch, es él quien la fija en la historiografía. Esta dualidad, con un claro componente étnico, fue establecida por disciplinas como la Lingüística y no deja de ser solamente una propuesta filológica. Sin embargo, los arqueólogos tratan durante años de adaptar a ella el registro; es más, aún lo intentan, como es patente, por ejemplo, en algunos trabajos de Almagro Gorbea (Almagro y Ruíz Zapatero 1992; Almagro 1994). Por el contrario, Burillo (1998) en un todavía reciente libro sobre los celtíberos, donde reúne y da una visión crítica de todo lo escrito sobre uno de los problemas que más preocuparon a Bosch -la iberización de los celtíberos o la celtiberización de los íberos-, permite ver los términos drásticos, y aún dramáticos, con que se aborda la contraposición de estos dos 
supuestos ámbitos étnico-culturales. El segundo de los planteamientos de Bosch que muestra que su pensamiento está en el fondo del que se alimenta parte de la producción historiográfica actual es esa idea en la que ya he insistido: la dinámica histórica, sea cual sea su escala, se presenta mediante una dicotomía: aborígenes y extranjeros.

Espero haber dejado clara la indudable calidad de Maestro de Pedro Bosch Gimpera, no sólo de la Escuela de Barcelona sino de toda la Arqueología española, a la que vertebró y dotó de una primera proyección social. Pero quizás lo que encierra una verdadera lección historiográfica es que de Bosch se puede decir aquello de que todos somos hijos de un lugar, de una época y de sus ideas, pero algunos más que otros.

\section{AGRADECIMIENTOS}

Javier Sánchez-Palencia nos facilitó el manuscrito original de M. ${ }^{a}$ Dolores Fernández-Posse. Carmen Herrero Valverde, Directora del Museo de San Isidro (Madrid), autorizó su publicación (11-XI-2014) dado su gran interés para la comunidad científica y como forma de participar de alguna manera en este homenaje del Consejo de Redacción de Trabajos de Prehistoria a M. ${ }^{\mathrm{a}}$ Dolores Fernández-Posse.

\section{BIBLIOGRAFÍA}

Almagro Gorbea, M. 1994: "Urbanismo en la Hispania céltica: castros y oppida". En M. Almagro Gorbea y A. M. Martín (eds.): Castros y oppida en Extremadura. Complutum Extra 4, Universidad Complutense. Madrid: 13-75.

Almagro Gorbea, M. y Ruíz Zapatero, G. (eds.) 1992: Paleoetnología de la Península Ibérica. Complutum Extra 2-3, Universidad Complutense. Madrid.

Álvarez Martí-Aguilar, M. 2005: Tarteso. La construcción de un mito en la historiografia española. Centro de Ediciones de la Diputación de Málaga. Málaga.

Bosch Gimpera, P. 1914: Grecia y la civilización crético-micénica. Estudio. Barcelona.

Bosch Gimpera, P. 1925: "Los pueblos primitivos de España”. Revista de Occidente 26: 153-154.

Bosch Gimpera, P. 1928: "Problemas de la colonización fenicia en España y del Mediterráneo Occidental". Revista de Occidente 60: 314-348.
Bosch Gimpera, P. 1929: "Problemas de la colonización griega en España”. Revista de Occidente 72: 312-339.

Bosch Gimpera, P. 1932: Etnología de la Península Ibérica. Ed. Alpha. Barcelona.

Bosch Gimpera, P. 1937: Espanya. Ed. 62. Barcelona.

Bosch Gimpera, P. 1945: La formación de los pueblos de España. Imprenta Univ. México.

Bosch Gimpera, P. 1969: "La Cultura de Almería". Pyrenae 5: 47-94.

Bosch Gimpera, P. 1980: Memòries. Biografies i Memòries 5. Ed. 62. Barcelona.

Burillo, F. 1998: Los celtíberos. Etnias y estados. Crítica. Barcelona.

Cabré Aguiló, J. 1942: “El rito céltico de incineración con estelas alineadas". Archivo Español de Arqueología 15: 339-344.

Caro Baroja, J. 1946: Los pueblos de España. Ensayo de Etnología. Ed. Laye. Barcelona.

Cartailhac, E. 1886: Les âges préhistoriques de l'Espagne et $d u$ Portugal. Ch. Reinwald. Paris.

Comas, J. 1963: "Bio-bibliografía de Pedro Bosch Gimpera”. En J. R. dos Santos Júnior (ed.): A Pedro Bosch Gimpera en el septuagésimo aniversario de su nacimiento. Instituto Nacional de Antropología e Historia, Universidad Nacional Autónoma de México. México: XXXI-LXIV.

Comas, J. (ed.) 1976: In Memoriam Pedro Bosch-Gimpera 1891-1974. Universidad Nacional Autónoma de México. México.

Cortadella i Morral, J. 1988: "M. Almagro y la idea de la unidad de España". Studia História 6: 17-25.

Cortadella i Morral, J. 1991: "La formación académica de Bosch Gimpera: de la filología griega a la protohistoria peninsular". En J. Arce y R. Olmos (eds.): Historiografía de la Arqueología y de la Historia Antigua en España (siglos XVIII-XX). Congreso Internacional (Madrid 1988): 161-166. Madrid.

Díaz Andreu, M. 1995: “Arqueólogos españoles en Alemania en el primer tercio del siglo XX. Los becarios de la Junta de Ampliación de Estudios: Bosch Gimpera". Madrider Mitteilungen 36: 79-89.

Fernández-Posse, M. ${ }^{a}$ D. 1998: La investigación protohistórica en la Meseta y Galicia. Ed. Síntesis. Madrid.

García y Bellido, A. 1952: "Protohistoria. Tartessós". En R. Menéndez Pidal (ed.): Historia de España I, 2. Espasa-Calpe. Madrid.

García Quintela, M. V. 1990: "Les peuples indigènes et la conquete romaine de l'Hispanie. Essai de critique historiographique". Dialogues d'Histoire Ancienne 16/2: 181-210.

Gilman, A. 1988: "Enfoques teóricos de la Arqueología de los ochenta". Revista de Occidente 81: 47-67.

Gilman, A. 1995: "Recent trends in the Archaeology of the Iberian Peninsula". En K. T. Lillios (ed.): The Origins of Complex Societies in Late Prehistoric

Trab. Prehist., 72, N. ${ }^{\circ}$ 1, enero-junio 2015, pp. 8-21, ISSN: 0082-5638

doi: $10.3989 /$ tp.2015.12141 
Iberia. International Monographs in Prehistory, Archaeological series 8. Ann Arbor: 1-6.

Maluquer de Motes, J. 1955: "El proceso histórico de las poblaciones peninsulares". Zephyrus 6: 145-169 y 241-255.

Martínez Navarrete, M. ${ }^{\text {a }}$ I. 1989: Una revisión crítica de la prehistoria española: la Edad del Bronce como paradigma. Ed. Siglo XXI. Madrid.

Martínez Santa Olalla, J. 1946: Esquema paletnológico de la península hispánica. Publicaciones del Seminario de Historia Primitiva del Hombre. Madrid.

Mata Carriazo, J. de 1947: "La Edad del Bronce". En R. Menéndez Pidal (ed.): Historia de España I, Espasa Calpe. Madrid: 755-852.

Mederos Martín. A. 1999: “El joven Bosch Gimpera y la primera reestructuración de la Prehistoria en España”. Boletín del Seminario de Arte y Arqueología LXV: 9-28.

Mélida Alinari, J. R. 1883: "Las Antigüedades de la Exposición y Minería. Revista de Archivos Bibliotecas y Museos IX: 294.

Paris, P. 1903-1904: Essai sur l'art et l'industrie de l'Espagne primitive. Ernest Leroux. París.

Pasamar, G. y Peiró, I. 1991: “Los orígenes de la profesionalización historiográfica española sobre Prehistoria y Antigüedad (tradiciones decimonónicas e influencias europeas)". En J. Arce y R. Olmos (eds.): Historiografía de la Arqueología y de la Historia Antigua en España (siglos XVIIIXX). Congreso Internacional (Madrid 1988): 73-77. Madrid.

Peiró, I. y Pasamar, G. 1990: “El nacimiento en España de la Arqueología y la Prehistoria (Academicismo y profesionalización, 1856-1936)"'. Kalathos 9-10: 9-30.
Pericot, L. 1963: "La Escuela arqueológica barcelonesa". En Problemas de la Prehistoria y la Arqueología Catalanas: II Symposium de Prehistoria Peninsular (Barcelona 1962): xvii-xxviii. Barcelona.

Pericot, L. 1976: "Algunos de mis recuerdos de BoschGimpera". En J. Comas (ed.): In Memoriam Pedro Bosch-Gimpera 1891-1974. Universidad Autónoma de México. México: 23-37.

Pijoan, J. 1908: "La cerámica ibérica a l'Aragó". Anuari del Institut d'Estudis Catalans II: 241-262.

Plácido Suárez, D. 1991: "La historiografía española sobre Sertorio". En J. Arce y R. Olmos (eds.): Historiografía de la Arqueología y de la Historia Antigua en España (siglos XVIII-XX). Congreso Internacional (Madrid 1988): 227-228.

Renfrew, C. 1990: Arqueología y lenguaje. La cuestión de los orígenes indoeuropeos. Ed. Crítica. Barcelona.

Schmidt, H.1915: Estudios acerca de los principios de la Edad de los Metales en España, Traducción por el Dr. P. Bosch-Gimpera. Comisión de Investigaciones Paleontológicas y Prehistóricas 8, Museo Nacional de Ciencias Naturales. Madrid.

Schulten, A. 1920. Hispania: geografía, etnología, historia. Académica. Barcelona.

Schulten, A. y Bosch Gimpera, P. (eds.) 1922: Fontes Hispanie Antiquae I. Universidad de Barcelona. Barcelona.

Siret, L. 1907: "A propos des potéries pseudo-myceniennes". L'Anthropologie XVIII: 277-299.

Siret, H. y Siret, L. 1887: Les premiers âges du métal dans le Sud-Est de l'Espagne: résultats des fouilles faites par les auteurs de 1881 à 1887. Antwerpen. Amberes. 